\title{
BMJ Global Health Natural hazards, disasters and violence against women and girls: a global mixed-methods systematic review
}

\author{
Alyssa Mari Thurston (D) , ${ }^{1}$ Heidi Stöckl (D) , ${ }^{2}$ Meghna Ranganathan (D) ${ }^{2}$
}

\begin{abstract}
To cite: Thurston AM, Stöckl H, Ranganathan M. Natural hazards, disasters and violence against women and girls: a global mixed-methods systematic review. BMJ Global Health 2021;6:e004377. doi:10.1136/ bmjgh-2020-004377
\end{abstract}

Handling editor Soumyadeep Bhaumik

- Additional material is published online only. To view please visit the journal online (http://dx.doi.org/10.1136/ bmjgh-2020-004377).

Received 5 November 2020 Revised 9 February 2021 Accepted 4 March 2021

\section{Check for updates}

(c) Author(s) (or their employer(s)) 2021. Re-use permitted under CC BY-NC. No commercial re-use. See rights and permissions. Published by BMJ.

${ }^{1}$ Department of Disease Control, Faculty of Infectious and Tropical Diseases, London School of Hygiene and Tropical Medicine, London, UK

${ }^{2}$ Department of Global Health and Development, Faculty of Public Health and Policy, London School of Hygiene and Tropical Medicine, London, UK

Correspondence to Alyssa Mari Thurston; alyssa.thurston@Ishtm.ac.uk; aly.thurston@gmail.com

\section{ABSTRACT}

Introduction Disasters triggered by climate and other natural hazards are increasing in frequency, severity and duration worldwide. Disasters disproportionately impact women and girls, with some evidence suggesting that violence against women and girls (VAWG) increases in disaster settings. Suggested risk factors for postdisaster VAWG include increased life stressors, failure of law enforcement, exposure to high-risk environments, exacerbation of existing gender inequalities and unequal social norms. We aim to systematically appraise the global literature on the association between disasters from natural hazards and VAWG.

Methods We conducted a systematic review using the following databases: Embase, Global Health, Medline, PubMed and Social Policy and Practice and searched grey literature. We included quantitative, qualitative or mixed-methods studies published in English language that examined the association between disasters from natural hazards and VAWG. We summarised the findings using a narrative synthesis approach.

Results of 555 non-duplicate records, we included a total of 37 quantitative, qualitative and mixed-methods studies. Among the quantitative studies, eight studies found a positive association between disaster exposure and increased VAWG, and four additional studies found positive associations with some violence types but not others. Qualitative findings offered insights into three hypothesised pathways: disaster exposure associated with (1) an increase of stressors that trigger VAWG; (2) an increase of enabling environments for VAWG and (3) an exacerbation of underlying drivers of VAWG.

Conclusion As the first known global systematic review on the relationship between disasters from natural hazards and VAWG, this review contributes to the evidence base. We were limited by the quality of quantitative studies, specifically study designs, the measurement of variables and geographic scope. The severe health consequences of VAWG and increasing frequency of extreme events means that rigorously designed and better quality studies are needed to inform evidence-based policies and safeguard women and girls during and after disasters.

\section{INTRODUCTION}

Over the past two decades, 7348 disasters triggered by natural hazards were recordednearly double the number recorded between

\section{Key questions}

What is already known?

- Disasters triggered by climate and other natural hazards are increasing in frequency, severity and duration worldwide.

- Disasters disproportionately impact women and girls and emerging evidence suggesting that violence against women and girls (VAWG) increases in disaster settings through various pathways.

What are the new findings?

- The current quantitative and qualitative evidence suggests that exposure to disasters caused by climatological, geophysical, hydrological and meteorological hazards (collectively termed 'natural') can increase VAWG in various settings.

- Exposure to disasters can increase VAWG through an increase of stressors that trigger VAWG; an increase of enabling environments for VAWG to occur; and an exacerbation of underlying drivers of VAWG.

What do the new findings imply?

- Our findings imply that disaster-related VAWG is both a public health and disaster management concern and must be addressed across policy and practice.

- There is an urgent need for gender-sensitive disaster risk reduction policies, inclusion of women in disaster management, promotion of social protection programmes, and establishment of coordination systems between disaster management, law enforcement and health authorities to prevent VAWG and treat the health consequences.

- More high-quality research with greater geographical scope and use of standardised exposure and outcome measures is critical to generate further knowledge on the scale of the issue and mechanisms.

1980 and 1999. ${ }^{1}$ Between 2008 and 2017, 84\% of all recorded disasters were climate related, ${ }^{2}$ and the number of people affected by floods and storms has significantly increased..$^{2-4}$ There is strong evidence that climate change induced by unsustainable human activity is a driving force for the changing frequency, severity and duration of extreme events. ${ }^{1-4}$ 
However, heightened exposure and vulnerability to natural hazards are rooted in structural challenges like poverty and inequalities, rapid population growth and urbanisation, migration and displacement, poor land use planning and management and the lack of resilient institutions. $^{5-8}$

Against this backdrop, women and girls bear a disproportionate burden of disaster-related impacts. ${ }^{7-14}$ Mortality rates of women from disasters are often much higher than those of men; for example, $90 \%$ of the 140000 deaths during the 1991 cyclone in Bangladesh were women. ${ }^{8-10}$ There are numerous explanations to the gendered impacts of disasters, including biological differences, gender discriminatory practices in relief efforts, lower access to information and resources, care responsibilities and gendered poverty. ${ }^{11}{ }^{12}$ At the policy level, women's perspectives in disaster management are also not adequately considered and met, ${ }^{12}{ }^{13}$ despite the affirmation of need by the Sendai Framework for Disaster Risk Reduction (DRR) 2015-2030 to integrate gender considerations for inclusive policy, strategies and practices in DRR. ${ }^{15}$

There is also growing evidence of the exacerbation of violence against women and girls (VAWG) during and after disasters, ${ }^{16-20}$ including violence by a non-partner or intimate partner, rape/sexual assault, as well as female genital mutilation, honour killings and the trafficking of women. ${ }^{21}$ There were reports of widespread rape after the 2010 Haiti earthquake, ${ }^{16}$ while intimate partner violence (IPV) was estimated to have increased by $40 \%$ in rural areas after the 2011 Christchurch earthquake in New Zealand. ${ }^{17}$

Various pathways have been suggested to understand the association between disaster exposure and VAWG. As with other emergency settings, disasters can increase risk factors for VAWG, like trauma and mental health issues; substance abuse; breakdown of family structures and social isolation; collapse and failure of law enforcement and services; and stressors from loss of housing and livelihoods. ${ }^{192}$ Prolonged recovery and reconstruction can also leave displaced women and girls in camps and shelters where they are at heightened risk of experiencing violence. ${ }^{192022}$ Disaster exposure may also exacerbate existing drivers of VAWG, like socioeconomic and gender inequalities, rigid social norms, and unbalanced power structures at various levels of the social ecology: household, community and macrolevels of society. ${ }^{192022}$

Increased VAWG after disasters may have dire health consequences for women across the life course. VAWG can lead to gynaecological complications from unintended pregnancies, unsafe abortions, miscarriages, sexually transmitted infections, poor overall health for mothers and babies, physical injuries, various mental health issues, and fatal outcomes from homicide or suicide. ${ }^{23}{ }^{24}$ Within postdisaster settings, the reduced capacity and access to health and emergency services can delay provision of timely and quality treatment, potentially worsening health outcomes. ${ }^{25}$

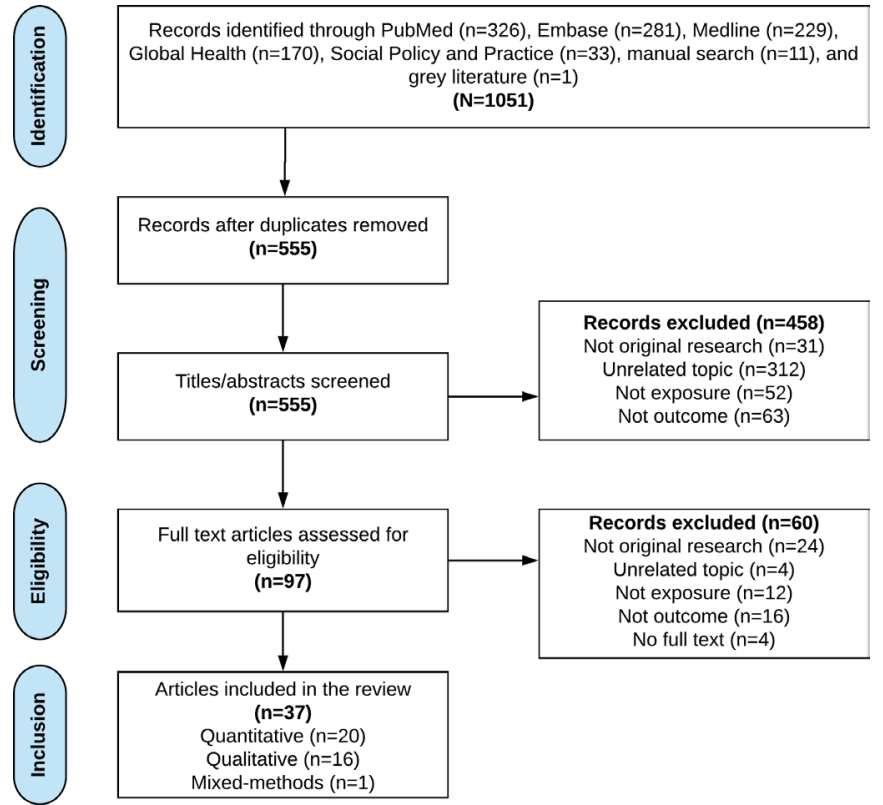

Figure 1 PRISMA flow diagram. PRISMA, Preferred Reporting Items for Systematic Reviews and Meta-Analyses.

Understanding how disaster exposure impacts VAWG is more important than ever to inform gender-sensitive policy in disaster management. ${ }^{1419}$ There is a dearth of critical and systematic appraisal of the current literature on the associations between disasters from natural hazards and VAWG. A review by Rezaeian ${ }^{26}$ on the associations between disasters and violence found that disaster exposure increased VAWG, including sexual violence, IPV and child abuse. However, the limited methodological rigour of this review and the outcome not specific to VAWG means there remains a gap in the literature. Contrary to these findings, a systematic review by Cerna-Turoff $e t a t^{22}$ on natural disasters and violence against children found no evidence for positive association, even when adjusted for gender. Other reviews on VAWG in emergency settings focus primarily on armed conflict, ${ }^{27} 28$ indicating a need for robust evidence on postdisaster VAWG within the development sector as well. The objective of this systematic review is to synthesise and assess the current quantitative and qualitative evidence on exposure to disasters due to natural hazards on the outcome of VAWG.

\section{METHODS \\ Search strategy and definitions}

We conducted a systematic review of the databases Medline, PubMed, Global Health, Embase and Social Policy and Practice to identify studies published until 29 June 2020. Our review followed PRISMA guidelines (online supplemental appendix 1). ${ }^{29}$ Our search strategy applied terms associated with three concepts: (1) violence; (2) women and girls; and (3) disasters caused by natural hazards (climatological, geophysical, hydrological and meteorological hazards) (online supplemental appendix 2). ${ }^{22}{ }^{28}$ We also conducted a manual search using Google Scholar, as well as a grey literature search of the websites of organisations including 
Table 1 Summary of study designs, quantitative measures, analysis type and associations between exposure and outcome in quantitative studies $(\mathrm{N}=20)$ and mixed-methods study $(\mathrm{N}=1)$

\begin{tabular}{|c|c|c|}
\hline Study design & No of studies & Reference \\
\hline Quasi-experimental & 21 & $37-4346-59$ \\
\hline Longitudinal & 2 & 4041 \\
\hline Cross-sectional & 19 & $37-39424346-59$ \\
\hline No comparison groups & 3 & $53-55$ \\
\hline Comparison groups & 16 & 37-39 $424346-52565859$ \\
\hline Measures of exposure and outcome variables & No of studies* & Reference \\
\hline \multicolumn{3}{|l|}{ Exposure variable } \\
\hline $\begin{array}{l}\text { Ecological } \\
\text { (eg, spatial data on residency and severity of disaster) }\end{array}$ & 6 & $40-435557$ \\
\hline \multicolumn{3}{|l|}{ Self-reported disaster experience } \\
\hline $\begin{array}{l}\text { Binary variable of affectedness } \\
\text { (eg, Were you affected by disaster?) }\end{array}$ & 1 & 39 \\
\hline Ordered categorical variable of affectedness & 2 & 3738 \\
\hline Proxy measures (eg, living in displacement camp) & 6 & 464749505458 \\
\hline Not specified or unclear & 6 & $4851-535659$ \\
\hline \multicolumn{3}{|l|}{ Outcome variable } \\
\hline Validated scale & 4 & 37495859 \\
\hline Experience of a range of violent acts & 8 & $39424346-48565859$ \\
\hline Experience of violence (general) & 9 & $38404750-55$ \\
\hline Other & 2 & 4157 \\
\hline Analysis type & No of studies & Reference \\
\hline Unadjusted or unclear & 9 & $394952-5759$ \\
\hline Adjusted or multivariate & 12 & $373840-4346-48505158$ \\
\hline Association between disaster exposure and VAWG & No of studies & Reference \\
\hline Exposure associated with increased VAWG & 8 & $373841-43465759$ \\
\hline Exposure associated with decreased VAWG & 0 & \\
\hline Exposure associated with no effect on VAWG & 5 & $3949-52$ \\
\hline Exposure associated with mixed effects on VAWG & 4 & 40474858 \\
\hline Cannot determine relationship & 4 & $53-56$ \\
\hline
\end{tabular}

*The number of studies does not equal 21 because some studies used multiple measures of exposure and/or outcome variables. VAWG, violence against women and girls.

the International Center for Research on Women, International Committee of the Red Cross, Human Rights Watch, Save the Children and UNICEF.

AMT and MR screened the titles and abstracts of articles, with full texts retrieved for articles that met the inclusion/exclusion criteria and both reviewed them against the same criteria.

Studies were included if they were constituted original research of any study design, published in peer-reviewed journals and in English language between the first logged records of databases and the date of the search (29 June 2020). No limits were set to geographical setting. We only included studies that assessed exposure to disasters (in line with the United Nations Office for DRR definition of disasters) caused by climatological, geophysical, hydrological and meteorological hazards (collectively termed 'natural hazards' in this review) (online supplemental appendix 3)..$^{30}$ Climate change itself was included as a hazard type, as some extreme events may be attributed to climate change and not to a specific natural hazard type. Biological and extraterrestrial hazards, as well as man-made disasters (eg, armed conflict, technological disasters) were excluded from this review. We included studies that assessed the outcome of VAWG of all types, including physical, psychological, sexual and/or financial (economic) abuse by an intimate or non-partner, as defined by the World Health Organization (WHO). ${ }^{32}$

\section{Quality assessment}

We used adapted versions of the National Institutes of Health (NIH) Quality Assessment Tool for Observational Cohort and Cross-Sectional Design and the Critical 
Appraisal Skills Programme (CASP) qualitative checklist to assess quantitative and qualitative studies respectively. ${ }^{33}$ Mixed-methods studies were assessed using both the NIH Quality Assessment Tool and CASP qualitative checklist, as well as the Mixed Methods Appraisal Tool. ${ }^{33-35}$ Based on the assessments, studies were scored between 0 and 10 .

\section{Data synthesis}

We consolidated the quantitative size and direction of effect where available. Key themes and illustrative quotes were compiled from qualitative findings and structured into hypothesised pathways from disaster exposure to VAWG. We used a narrative synthesis approach to synthesise the findings from all studies. ${ }^{36}$

The protocol was registered on the PROSPERO international prospective register of systematic reviews (CRD42020207911).

\section{Patient and public involvement}

There was no patient or public involvement in this review.

\section{RESULTS}

The search resulted in 1051 abstracts. After removing duplicates, the titles and abstracts of 555 records were screened against the inclusion/exclusion criteria, resulting in 97 full-text records assessed for eligibility using the same inclusion/exclusion criteria. Thirty-seven records were included in this review. For details, see figure 1.

\section{Study characteristics}

Of the 37 studies included in this review, 20 were quantitative, 16 qualitative and 1 was mixed-methods design. The studies included were set in 15 low-income, middleincome and high-income countries and one region (subSaharan Africa) (online supplemental appendix 4). The studies assessed exposure to disasters caused by nine different natural hazard types, most frequently, exposure to earthquakes $(40.0 \%)$, hurricanes $(19.5 \%)$ and tsunamis $(12.5 \%)$. A range of violence types were examined in relation to disaster exposure, primarily physical, psychological and sexual violence. Some studies also examined femicide, controlling or aggressive behaviour, forced early marriage and financial violence. Seventeen out of 37 studies examined VAWG caused by multiple perpetrator types versus one type. $37.0 \%$ of perpetrators were current or former intimate partners, $15.1 \%$ family members, $12.3 \%$ strangers, $11.0 \%$ authority figures, $8.2 \%$ friends/neighbours and $16.5 \%$ unspecified or other types of perpetrators.

\section{Summary of quantitative studies}

All 20 quantitative studies and one mixed-methods study had quasi-experimental designs: two were cohorts, and 16 had comparison groups, such as predisaster and postdisaster exposure, exposed or not exposed to the disaster, or different levels of disaster exposures. Three studies did not have comparison groups and reported postdisaster prevalence of reported VAWG. There was wide variability in the confounders used in adjusted analyses, with the most common measures used across studies being, age, education status, marital status and characteristics of partners for studies with IPV as the outcome variable. Nine studies did not conduct an adjusted analysis or did not specify the variables they adjusted for in their analysis (tables 1 and 2).

\section{Measures of exposure and outcome variables}

The quantitative results were based on various measures of exposure and outcome variables (table 1). For disaster exposure, studies often used ecological measures such as spatial data on respondents' residency and the disaster-affected geographic area at a defined time point. Another common exposure measure was using proxy indicators like evacuation status during the disaster or postdisaster residence in displacement camps. Three studies used self-reported disaster experience. ${ }^{37-39}$ Only six out of 21 studies measured different levels of disaster exposure, with levels measured ecologically by mapping disaster intensity levels (eg, annual precipitation for drought severity $)^{40-43}$ or by using scales to measures selfreported disaster experiences. ${ }^{37} 38$ Only two studies measured disaster exposure more than once over time. ${ }^{4041}$

Most studies measured VAWG as the outcome variable using general self-reported experiences of violence (eg, assault, harassment) or experiences of a range of violent acts (eg, being pushed, slapped), which included lifetime and/or predisaster/postdisaster prevalence (table 1). Only four studies used accepted and validated measurement tools like the Conflict Tactics Scale or the Women's Experience with Battering Scale, ${ }^{44} 45$ and only 12 out of 21 studies measured VAWG outcomes within 12 months of exposure to disaster(s). More than half $(\mathrm{n}=14)$ used surveys constructed for studies, while others used Demographic Health Surveys $(n=2)$, other national surveys $(n=4)$, hospital data $(n=1)$ or police reports/help line calls $(n=1)$.

\section{Associations between disaster exposure and VAWG}

Out of 20 quantitative studies and one mixed-methods study, eight studies found positive associations between disaster exposure and the measured violence outcome (table 1). Of these studies, IPV was most commonly associated with disaster exposure in four studies. ${ }^{37} 414246 \mathrm{In}$ Spain, heat waves between 2008 and 2016 were associated with increased IPV risk $(R R=1.02 ; \mathrm{p}<0.001)$ and intimate partner femicide $(R R=1.40 ; p=0.048)$, one to three days after the extreme heat event. ${ }^{41}$ In the USA, exposure to Hurricane Ike in 2008 was significantly associated with increasing the odds of boys physically $(\mathrm{OR}=3.19 ; \mathrm{p}<0.01)$ or sexually assaulting $(\mathrm{OR}=3.73 ; \mathrm{p}<0.01)$ dating partners, ${ }^{46}$ while exposure to Hurricane Katrina increased the risk of women experiencing violent acts by intimate partners by 5-8 times. $^{37}$ In India, the odds of IPV was much higher among women living in states severely $(\mathrm{OR}=1.98 ; \mathrm{p}<0.001)$ and moderately $(\mathrm{OR}=1.85 ; \mathrm{p}<0.001)$ affected by tsunamis compared with those living in an unaffected state. ${ }^{42}$ 


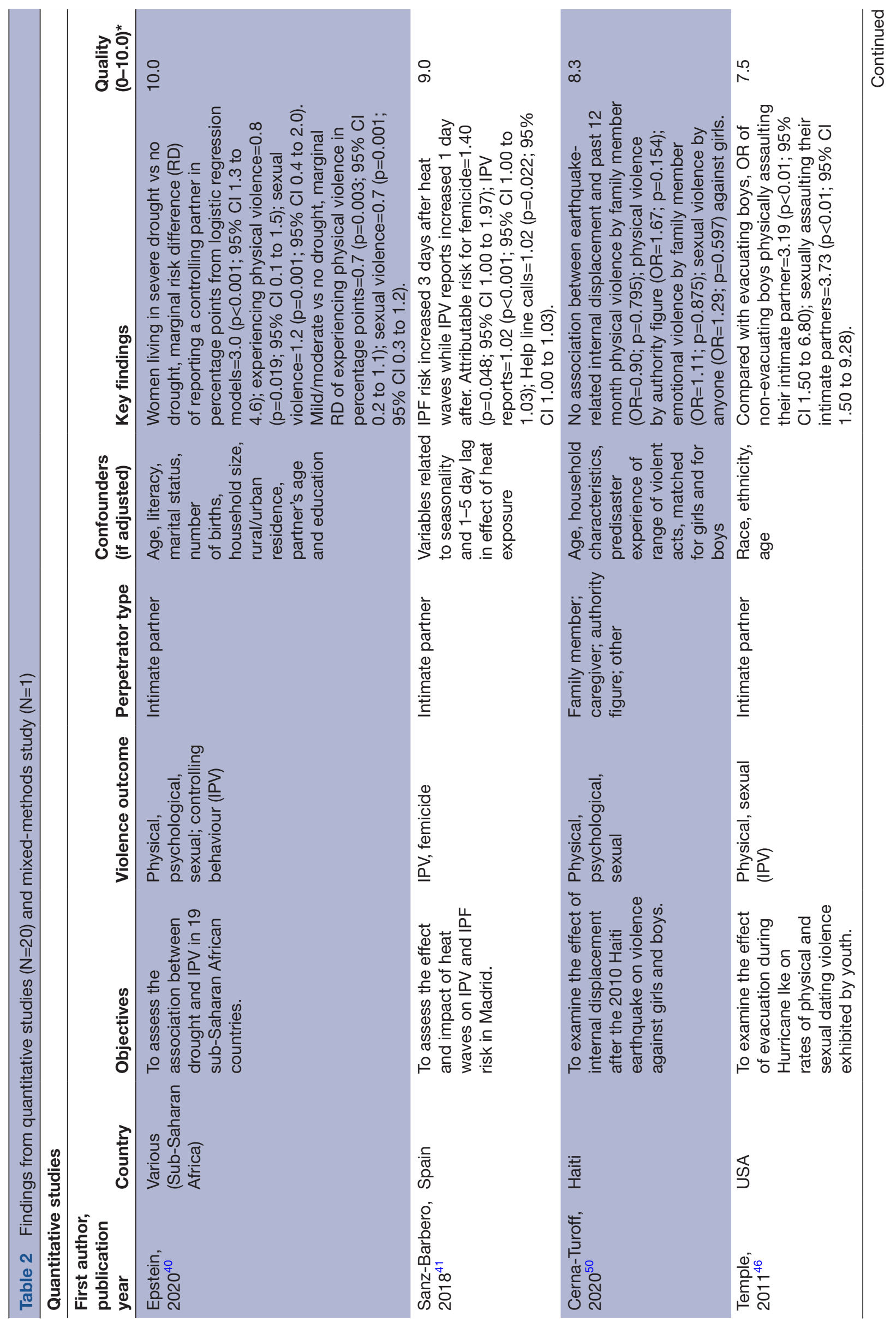




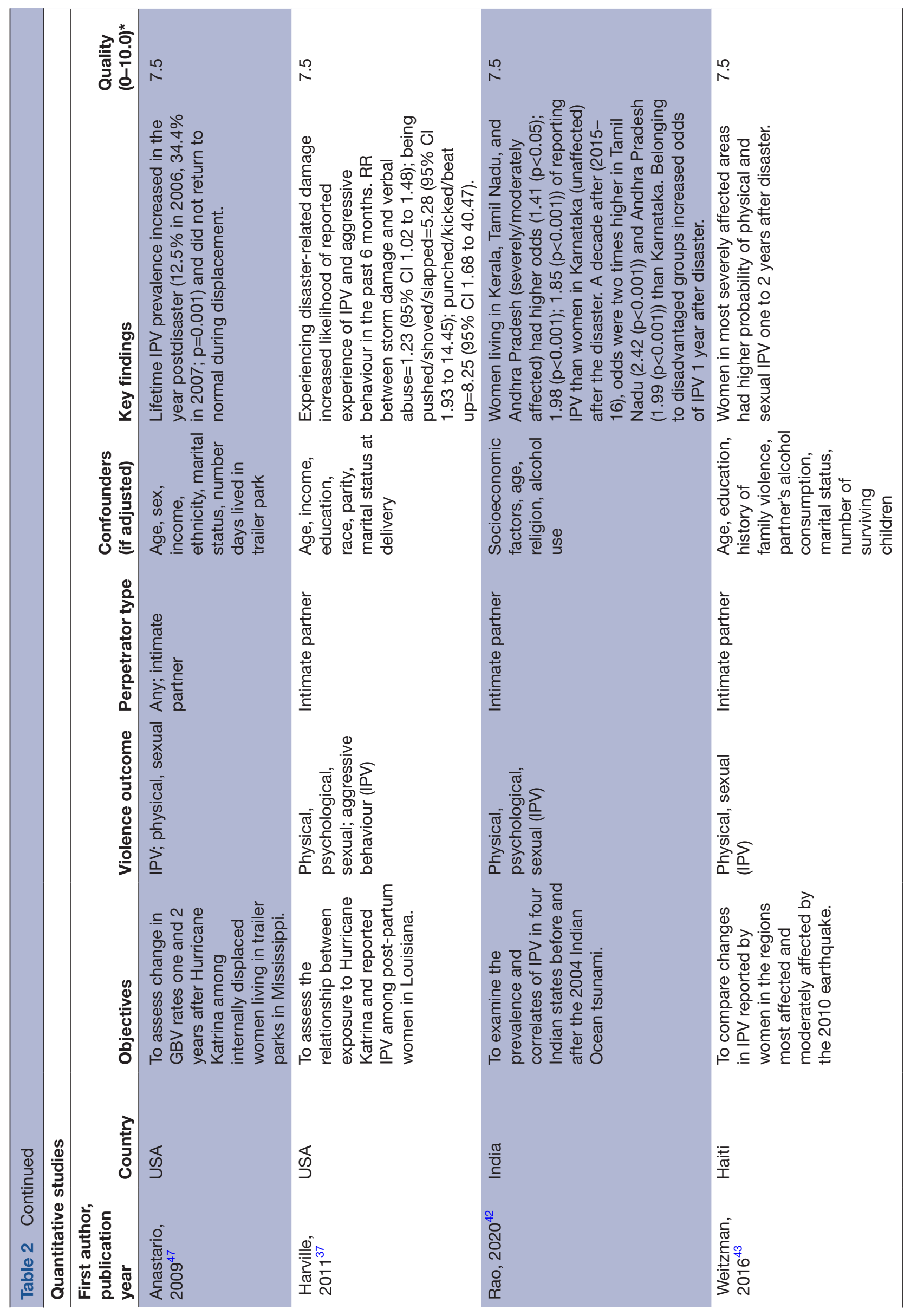




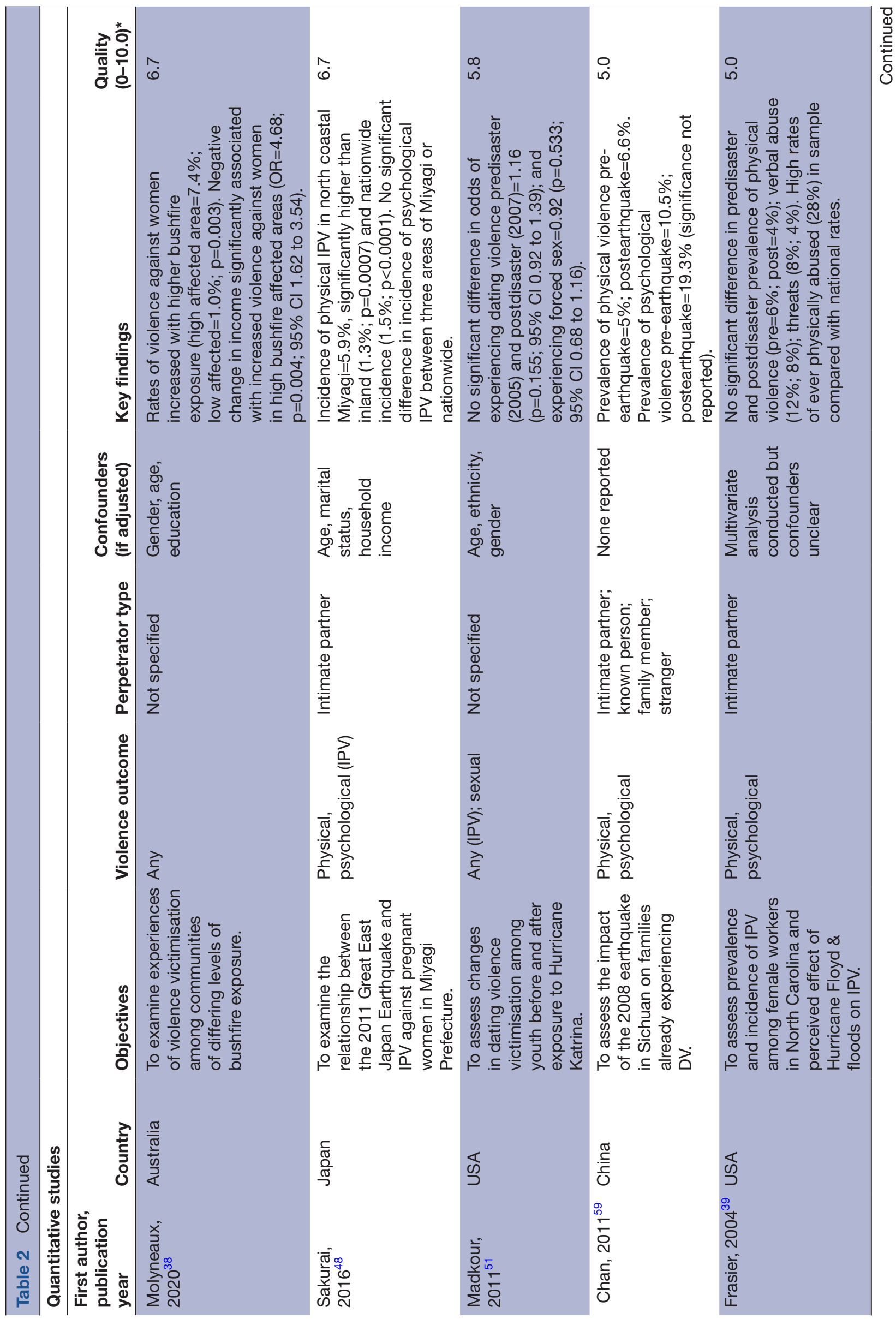




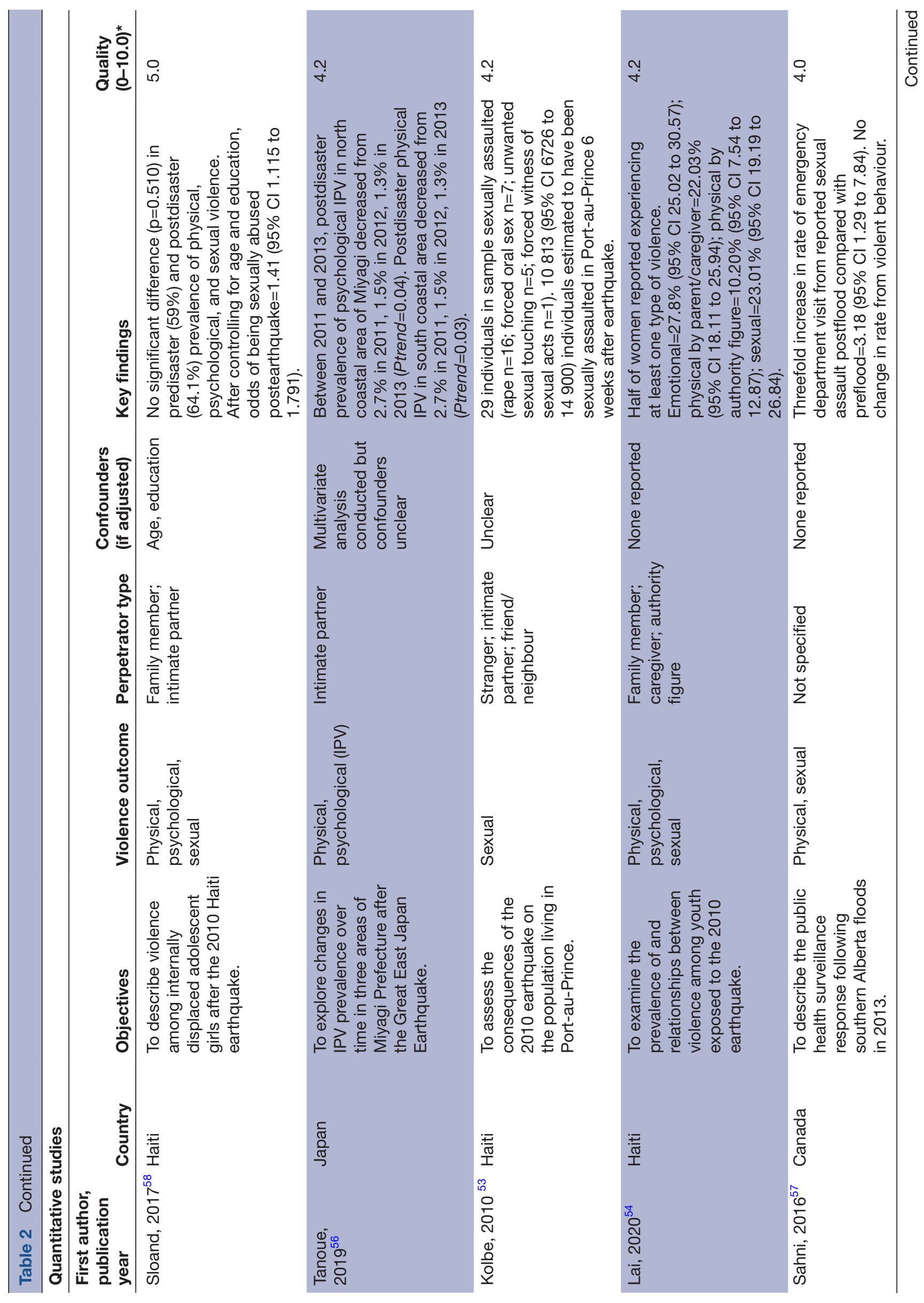

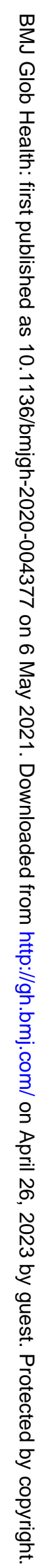




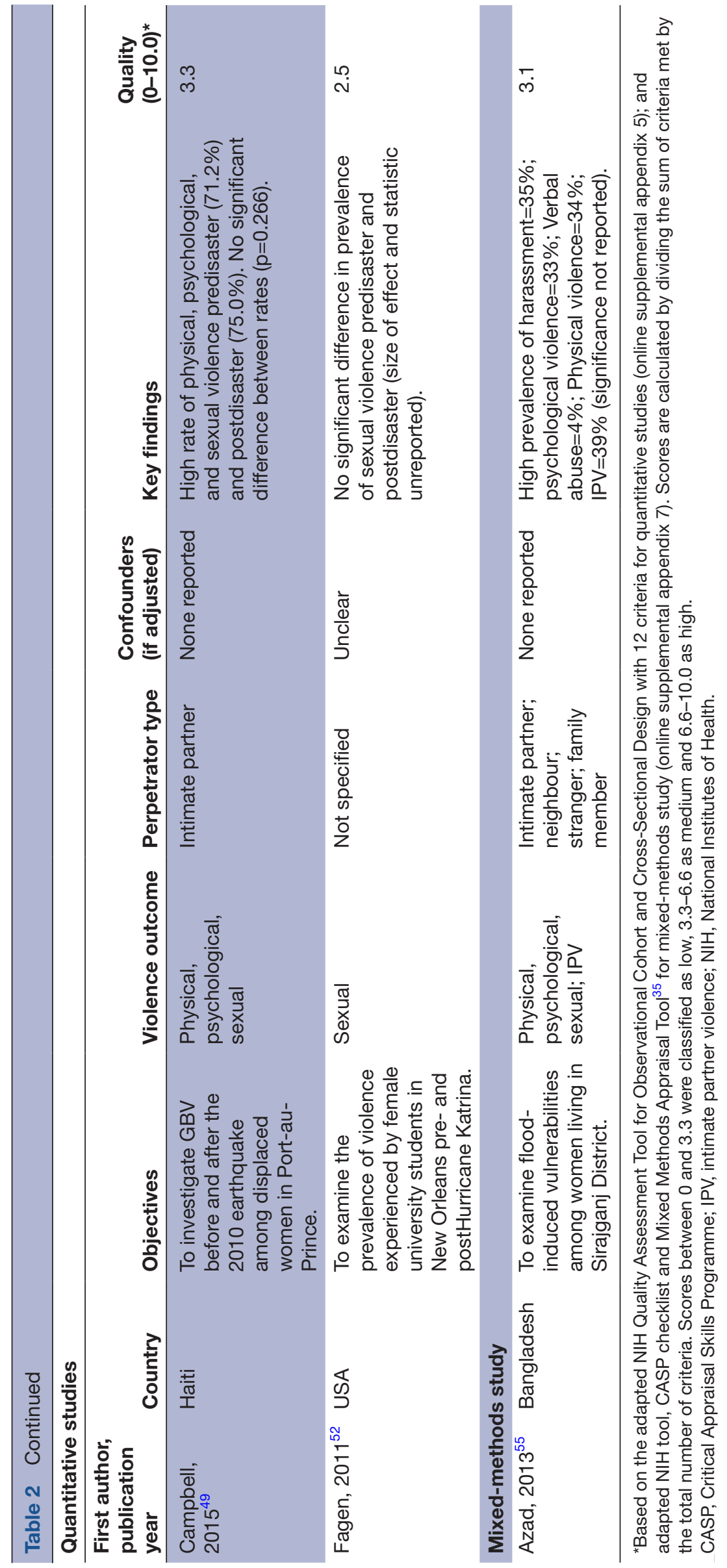


Three additional studies found associations between disaster exposure and IPV, but not other types of VAWG. ${ }^{40} 48$ Evidence from across sub-Saharan Africa showed significant increase in risk of physical and sexual IPV among women living in moderate and severe drought compared with women living in no drought, but no association was found for psychological violence. ${ }^{40}$ Similarly in Japan, postearthquake prevalence of physical IPV against pregnant women was significantly higher in affected areas compared with the national prevalence $(p<0.0001)$ but there was no difference in psychological violence. ${ }^{48}$ Meanwhile, hurricane exposure in the USA significantly increased $(\mathrm{p}=0.001)$ reported lifetime IPV prevalence one year $(12.5 \%)$ and two years $(34.4 \%)$ postdisaster, but did not change prevalence of sexual violence. ${ }^{47}$

Of the five studies that found no association between disaster exposure and VAWG, two studies commented on exceptionally high rates of predisaster VAWG ${ }^{39}{ }^{49}$ While there was no change in IPV prevalence among hurricaneexposed and flood-exposed women in the USA, nearly one-third of the women reported ever being physically abused-much higher than national rates. ${ }^{39}$ Similarly, one study found no difference in pre-earthquake and postearthquake VAWG in Haiti, but prevalence of abuse in the sample was extremely high both before $(71.2 \%)$ and after $(75.0 \%)$ the disaster. ${ }^{49}$ The other three studies that found no associations had the same subpopulation of adolescent girls. Earthquake-related displacement in Haiti was not associated with increased odds for any form of violence against girl (aged 13-17), ${ }^{50}$ while exposure to Hurricane Katrina had no effect on risk of sexual violence among girls (aged 12-18) and female university students. ${ }^{5152}$

The direction of effect for four studies from Bangladesh, Haiti and Japan could not conclusively be determined, as postdisaster prevalence of VAWG was reported without comparison to predisaster prevalence or a comparison group with different exposure status. However, all of these studies showed high prevalence of postdisaster VAWG. Two studies from Haiti reported high prevalence of postearthquake VAWG in their respective samples. ${ }^{5354}$ Weighting sampled household data to represent commune population, one study estimated that 10 813 individuals were sexually assaulted in Port-au-Prince after the 2010 earthquake. ${ }^{53}$ In the second study set in Haiti, half of the women and girls reported experiencing at least one type of violence postearthquake, with $23 \%$ reporting sexual violence. ${ }^{54}$ In Bangladesh, over $30 \%$ of sampled women had experienced a range of violence. ${ }^{55}$ The prevalence of IPV in different areas of Miyagi Prefecture declined over two years after the 2011 Great East Japan Earthquake, suggesting that earthquake exposure may have impacted the higher prevalence reported immediately postdisaster. ${ }^{56}$

There was limited consensus on findings from studies set within the same geographical setting. Evidence from North America on hurricane and flood exposure found contradictory effects, with four studies finding associations with physical, sexual and psychological violence, ${ }^{37464757}$ and three studies finding no effect. ${ }^{395152}$ All six studies set in Haiti examined earthquake exposure, with one study finding an increase in physical and sexual IPV following the disaster. ${ }^{43}$ Another study found that the odds of adolescent girls reporting sexual abuse increased after adjusting for age and education, while it is important to note that $61 \%$ of girls in this study did not respond to questions about pre-earthquake and postearthquake abuse. ${ }^{58}$ Two other studies found no effect, ${ }^{49} 50$ and the remaining two studies with no comparison groups described high rates of postearthquake VAWG. ${ }^{5354}$

Meanwhile, findings from across the Asia and Pacific region largely supported the positive association between disaster exposure and VAWG. Disaster exposures in Australia, China, India and Japan were all associated with increased risk or prevalence of VAWG. ${ }^{38} 424859$ Interestingly, the odds of IPV increased with higher levels of tsunami exposure in India, with the odds remaining two times higher even 10 years after the event among those that were most severely exposed and belonged to disadvantaged groups. ${ }^{42}$ In Australia, the odds of VAWG was five times higher in communities most severely affected by bushfires and for households that had experienced postdisaster reductions in income. ${ }^{38}$

Some authors of quantitative papers put forward ideas of hypothesised pathways from disaster exposure to increased VAWG but none were tested empirically. Many studies suggested poor mental health and related substance abuse as possible triggers of gendered violence. ${ }^{38} 40-4246474958$ Poor mental health was linked to postdisaster stressors like poverty, food insecurity, unemployment and lack of social support that were themselves risk factors for VAWG. ${ }^{40}{ }^{53}$ One study mentioned the failure of law enforcement and displacement camps as high risk environments in postdisaster settings. ${ }^{53}$ Other hypothesised pathways were rooted in social norms, gender inequalities and financial dependence of women on men. ${ }^{4042} 49$ Interestingly, one study that found no effect of hurricane exposure on violence against female students in the USA postulated that the sense of community on campus and available social support were protective factors. ${ }^{52}$

\section{Summary of qualitative studies}

Qualitative findings from 16 studies and one mixedmethods study $(\mathrm{N}=17)$ all described increased VAWG after disaster exposure (see table 3 ). A range of themes emerged from these studies on the mechanisms between disaster exposure to increased VAWG. These emergent themes from all studies are organised here into three overarching pathways: (1) disaster exposure associated with increase of stressors that trigger VAWG; (2) disaster exposure associated with increase of enabling environments for VAWG and (3) disaster exposure associated with exacerbating underlying drivers of VAWG. 


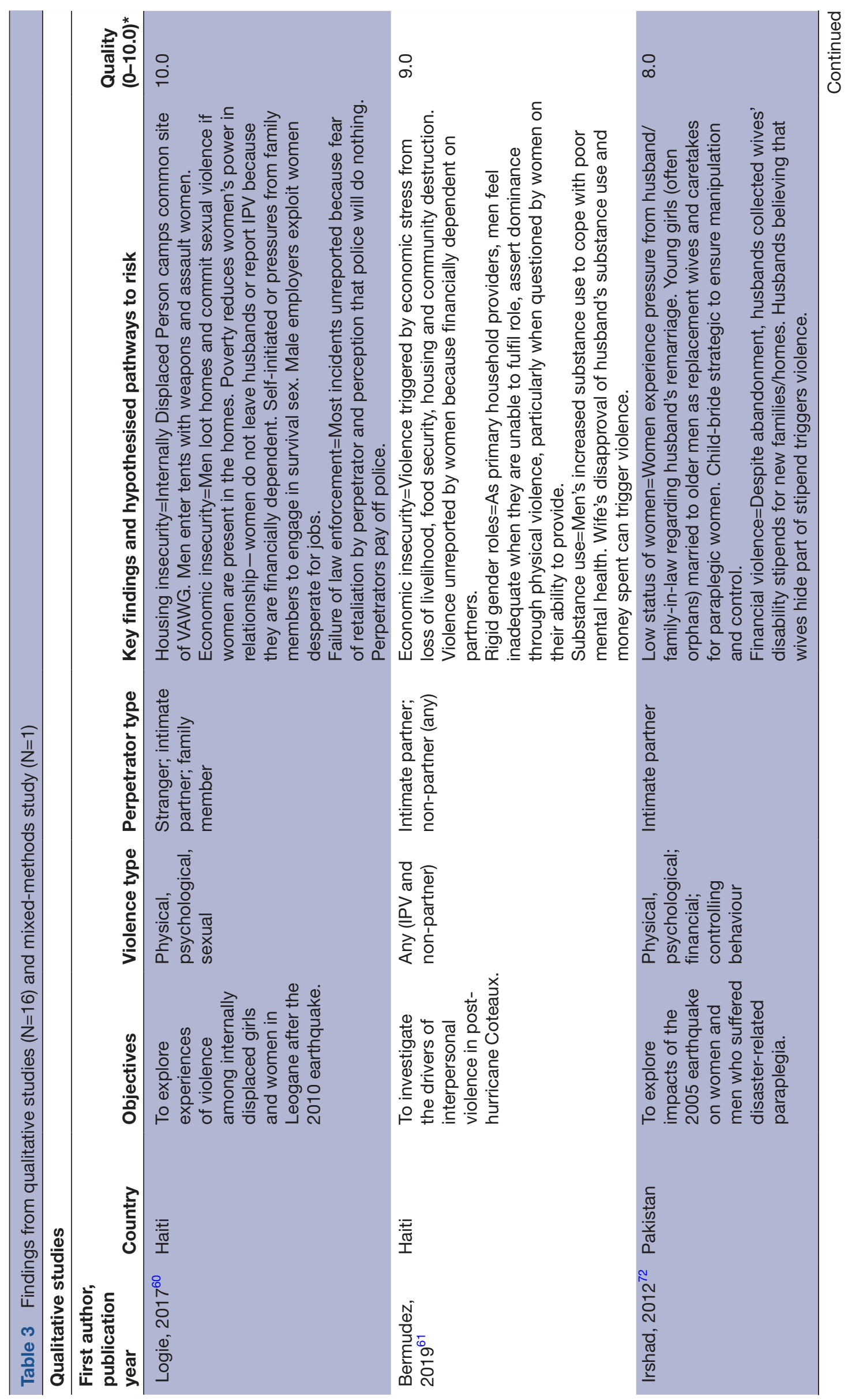




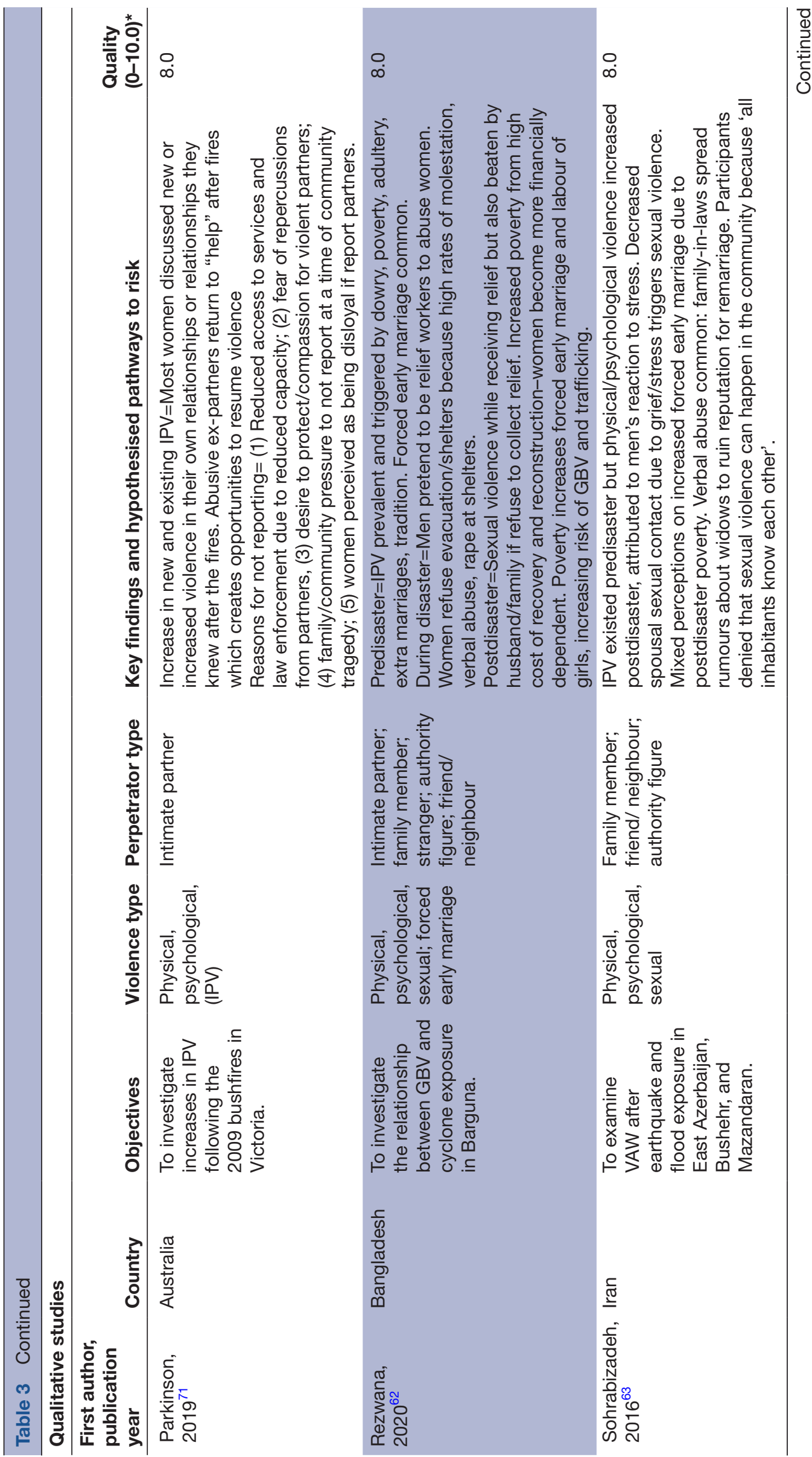




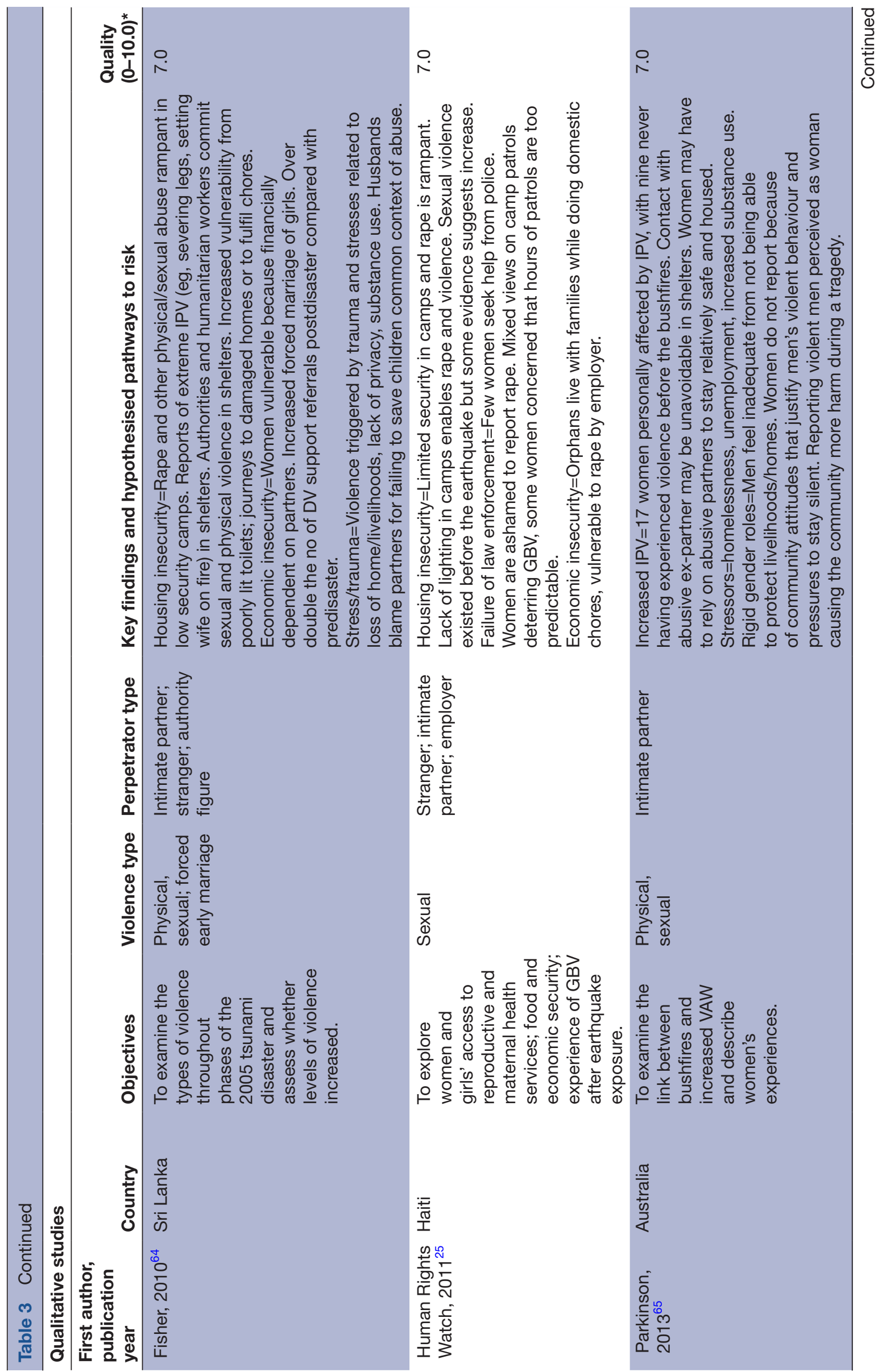




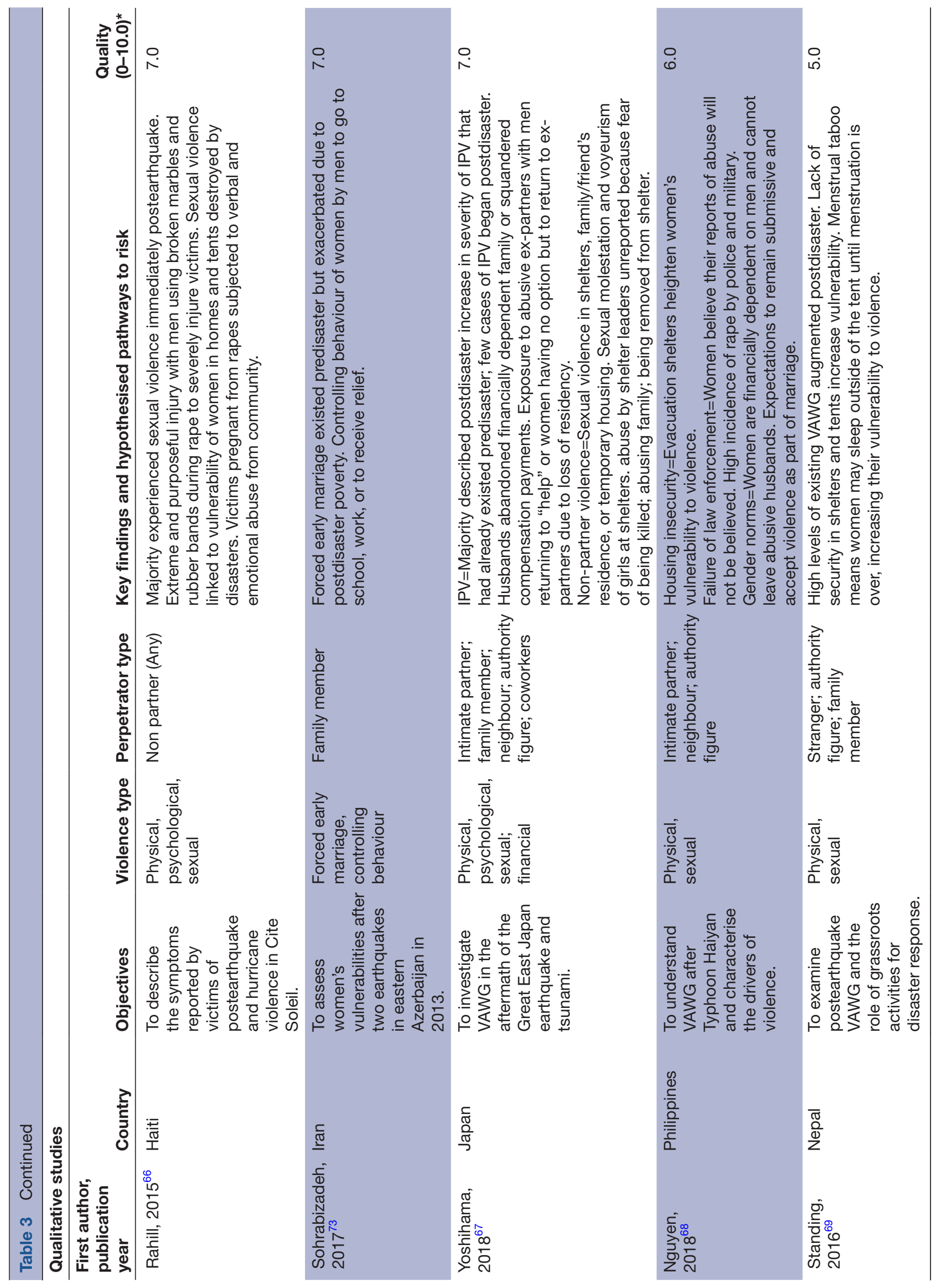

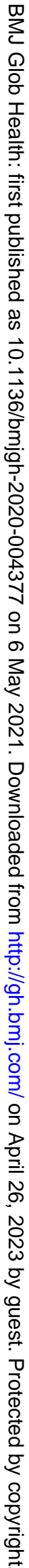




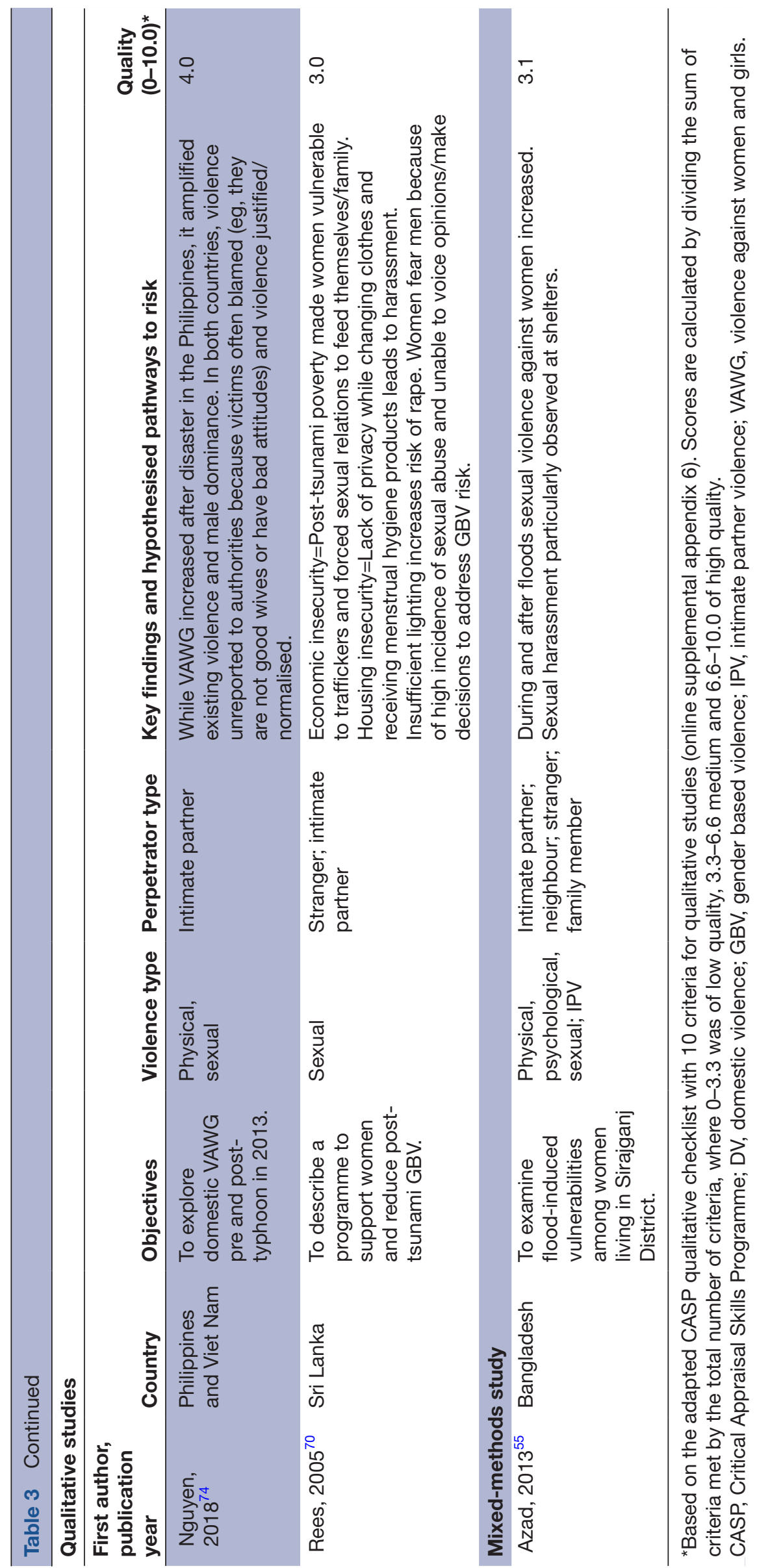


Pathway 1: disaster exposure associated with increase of stressors that trigger VAWG

Across many of the studies, VAWG was often triggered by three stressors that emerged in postdisaster settings: (1) housing insecurity; (2) economic insecurity and (3) trauma and mental health issues.

\section{Housing insecurity}

Almost all studies discussed women's heightened risk of violence caused by housing insecurity. ${ }^{25} 60-70$ The lack of privacy and security at temporary housing like evacuation shelters and displacement camps led to high rates of primarily sexual violence including rape, harassment, molestation and unwanted sexual contact. Violence was perpetrated by intimate partners, family members, strangers, community members and authority figures like police or leaders of evacuation shelters. In Bangladesh, perpetrators were also men who pretended to be relief workers to gain access to and abuse women. ${ }^{62}$

Extreme forms of postdisaster VAWG in displacement camps were reported. Women in Sri Lanka described partners setting wives on fire or severing their legs. ${ }^{64}$ In Haiti, perpetrators used broken marbles or rubber bands to rape and severely injure women. ${ }^{66} \mathrm{~A}$ key respondent from Haiti described the realities of rampant VAWG in displacement camps and the intersections with other stressors $^{60}$ :

When the earthquake just happened, all the time they are raping somebody or commit a violent act. Because there is no security in the tents. You may be in a tent and they set it on fire. There are no jobs. (Key respondent; Logie $e t$ $a l^{60}$, Haiti)

Loss of housing also allowed for abusive ex-partners to re-enter survivors' lives in different ways. In Australia, there were risks for victims coming into contact with abusive ex-partners in community evacuation shelters. ${ }^{65}$ For some women, IPV resumed when abusive ex-partners returned under the pretext of helping out or when women had no options but to reside with violent partners to stay relatively safe from disasters. ${ }^{6567} 71$

\section{Economic insecurity}

Economic insecurity in the aftermath of disasters was a major trigger of VAWG. In Haiti, postdisaster poverty and lack of policing resulted in men looting homes and assaulting women found in the homes. ${ }^{60}$ In Iran and Japan, economic violence was also perpetrated by husbands abandoning their financially dependent families or squandering compensation payments. ${ }^{67} 72$ Economic insecurity also served to increase women's vulnerability to VAWG. A recurring theme across studies was that financial dependence of women on their partners was augmented postdisaster. This increased their vulnerability to VAWG as they would not report or leave abusive partners. ${ }^{60-62646568}$ For some survivors, enduring violence may be preferrable to losing the household's breadwinner, as this quote suggests $^{61}$ :
I think this is the reason why women think twice before [reporting]. They see that they sentence the man for 10 years. Who is going to feed the house? Therefore, they don't make any complaints. (Male respondent; Bermudez et al. ${ }^{61}$, Haiti)

Poverty also drove some women to engage in transactional sex, while some employers took advantage of desperate, job-seeking women with sexual coercion in Bangladesh, Haiti and Sri Lanka. ${ }^{606170}$ Across South Asia and Iran, studies confirmed that forced early marriage or labour of young girls increased due to postdisaster poverty. $^{62647273}$

\section{Trauma and mental health issues}

Trauma and mental health issues often led to VAWG through various pathways. Decreased sexual contact between spouses due to wives and/or husbands coping with grief and stress triggered IPV in postdisaster Iran. ${ }^{63}$ Increased substance abuse by men struggling with poor mental health was a risk factor for VAWG across many postdisaster settings. ${ }^{61} 64656774$ Wives expressing disapproval of their husbands' use and money spent on alcohol and drugs was a scenario that triggered IPV in postdisaster Haiti and Viet Nam. ${ }^{6174}$ In Australian communities that suffered extreme tragedy and loss from bushfires, community-level empathy for traumatised men pressured women to not report abusive partners, while some survivors themselves felt compassion towards their partners and did not want to report IPV. ${ }^{71}$

Pathway 2: Disaster exposure associated with increase of enabling environments for VAWG

The studies described how postdisaster environments often heightened risks that enabled VAWG. For example, failures of law enforcement after disasters created environments that allowed for rampant VAWG in both high and low-income and middle-income settings, particularly in displacement camps and shelters. ${ }^{606465686971}$ Limited police presence was an issue in itself, but improper conduct of police fostered mistrust among women and those experiencing VAWG. Perceptions and realities of officers not taking reports seriously, not doing anything, shaming victims, taking bribes from perpetrators or sometimes committing VAWG themselves meant that women would not report abuse or seek help from law enforcement. $^{6064686974}$ In the aftermath of bushfires in Australia, police officers discouraged and trivialised reports of IPV ${ }^{65}$ :

So much has been justified as a result of the fires... so much has been fobbed off. So many women have gone to police and been told by police, 'Things will settle down again'. The responsibility is back on the women. (Health professional; Parkinson and Zara ${ }^{65}$, Australia)

The postdisaster displacement camp and shelter environments were also enablers of VAWG. The lack of privacy from open-planned evacuation shelters and insecurity from the lack of doors, walls and locks in displacement camps heightened VAWG in Haiti, Japan 
and Nepal. ${ }^{25} 606769$ Limited consideration of women's needs in camps created opportunities for violence and abuse. In Sri Lanka, women receiving menstrual products in view of men led to harassment in camps, ${ }^{70}$ while severe menstrual taboo in Nepal meant that some women slept outside of tents until menstruation was over, increasing their risk of experiencing violence. ${ }^{74}$ Poor lighting in these settings and lack of gender-segregated water, sanitation and hygiene facilities were also risky for women. ${ }^{25} 64676970$

\section{Pathway 3: disaster exposure associated with exacerbating underlying drivers of VAWG}

Many qualitative studies described existing high rates of VAWG before disaster exposure, ${ }^{25626367697174}$ indicating that underlying drivers of VAWG were already present in many settings that experienced a postdisaster increase. For example, the low status and agency of women and girls, combined with the effects of postdisaster poverty, facilitated an increase in forced early marriage of girls and women engaging in transactional sex to support themselves and those in their care. ${ }^{60626473}$

Rigid gender roles were also key underlying drivers of VAWG, particularly IPV. Studies from Australia, Haiti and Viet Nam described how VAWG triggered by stressors related to housing, income and employment was often rooted in men feeling inadequate in providing for financially dependent wives and children. ${ }^{60} 6574$ The intersections of gender roles, financial dependence of women on men, as well as substance use are exemplified in this quote by a male perpetrator in Viet $\mathrm{Nam}^{74}$ :

When we men came home after a night of drinking alcohol, we often lost our temper. Imagine a wife is complaining about financial issues and blaming one for being lazy. This made us men very frustrated and we often responded with violence. (Male respondent; Nguyen and Rydstrom ${ }^{74}$, Viet Nam)

Women in Australia and Viet Nam that experienced postdisaster IPV were sometimes blamed by their families or police as not fulfilling their role in caring for their husbands. ${ }^{65} 74$ In Iran, the double standards of gender roles were particularly evident among those disabled from disaster exposure. ${ }^{72}$ Wives were expected to become caretakers of their disabled husbands who were no longer able to provide for the family. Meanwhile, remarriage for husbands with disabled wives was perceived as normal, as wives could no longer fulfil their duties. ${ }^{72}$

\section{DISCUSSION}

Our systematic review of 37 studies clearly suggests that disasters caused by climate related or other natural hazards can increase VAWG across various settings. Eight out of 20 quantitative studies found an association between disaster exposure and increased VAWG, and an additional four studies found positive associations between exposure and some types of violence. Nearly half of all quantitative studies found that disaster exposures were associated with increased IPV across high-income, middle-income and low-income settings. While study designs and lack of comparison groups for four studies set in Bangladesh, Haiti and Japan limits the ability to draw firm conclusions, all these studies found high rates of postdisaster VAWG, speculated to have increased from disaster exposure. Importantly, no study found that disaster exposure was associated with decreased VAWG.

Three potential pathways emerged from the qualitative and quantitative studies with positive associations between disaster exposure and increased VAWG: (1) disaster exposure increased stressors that trigger VAWG, such as poor mental health, loss of housing and livelihoods; (2) disaster exposure increased enabling environments for VAWG, including poor law enforcement and risky postdisaster housing environments and (3) disaster exposure exacerbated underlying drivers of VAWG, for example, gender inequalities and worsened social norms. Together, these pathways informed our conceptual framework outlined in figure 2.

These hypothesised pathways are supported by nonempirical studies and grey literature ${ }^{112075}$ including some that compare the postdisaster environments caused by natural hazards and armed conflict. ${ }^{7677}$ Some argue that in both, an accumulation of stressors from displacement, poverty, poor mental health and increased substance use, and collapse of policing and social order can trigger VAWG. ${ }^{76}$ Yet unlike armed conflict that begins and ends with the destruction to social structures, ${ }^{78}$ some studies argue that disasters caused by natural hazards can increase altruism, social cohesion or women's economic participation in previously male-dominated spaces and may have protective effects on postdisaster VAWG. ${ }^{79-82}$ This premise, however, is not well supported by this present review and no study suggested any protective effects of disaster exposure.

Of the five quantitative studies that found no association between disaster exposure and VAWG, two studies had samples with exceptionally high existing baseline levels of VAWG, which may have reduced participants' ability to recall nuanced differences in violence before and after disaster exposure. The other three studies that found no effect assessed disaster exposure on violence against young girls only and had poor measurement quality. Furthermore, it is well documented that there remains significant under-reporting of VAWG either due to measurement issues or participant reluctance to disclose violence. ${ }^{21}{ }^{83}$ Many qualitative studies included in this review described under-reporting of VAWG in postdisaster settings due to failures of law enforcement, silencing by communities, fear of repercussions from perpetrators, financial dependence on violent partners or survivors' empathy for abusive partners. Thus, the data and accounts of postdisaster VAWG presented in the current literature likely underestimates the true scope of the issue. On the contrary, it may be possible that VAWG reported in postdisaster settings may not reflect a true increase in VAWG after the exposure, but an increase 


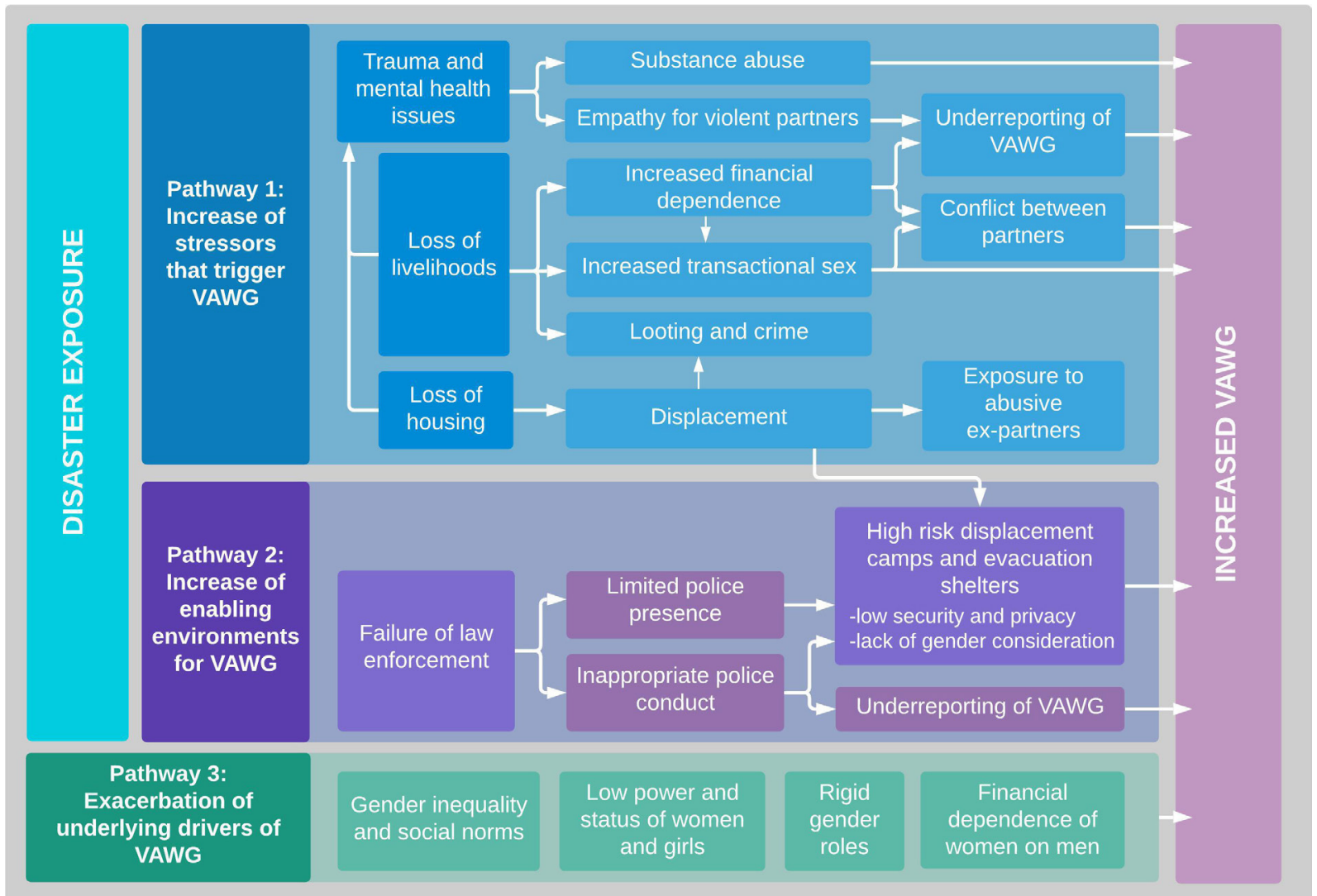

Figure 2 Conceptual framework of hypothesised pathways from disaster exposure to increased VAWG from all included studies. The exposure includes disasters caused by climatological, geophysical, hydrological and meteorological hazards and associated with climate change. Increased VAWG includes outcomes of physical, psychological (including emotional and verbal), sexual and financial violence. VAWG, violence against women and girls.

in reporting mechanisms (eg, those offered by humanitarian actors) that capture existing high levels of VAWG.

Beyond disasters caused by the natural hazardsexplored in this review, VAWG in the context of other threats like biological hazards also merits attention. The COVID-19 pandemic has increased global rates of VAWG,${ }^{84-86}$ with some overlaps in the theorised pathways between pandemics and VAWG and this present study, including declining mental health; economic insecurityrelated stressors; and pressures related to men's roles as income earners. ${ }^{85}$ During the 2013-2015, West Africa Ebola outbreak, school closures and quarantine measures to contain the virus increased exposure of women to abusers in the home,${ }^{87}$ similar to current global lockdown measures to reduce COVID-19 transmission. ${ }^{84-86}$

\section{Strengths and limitations}

As the first known global systematic review examining the associations between disasters caused by natural hazards and VAWG, this review adds to the much-needed evidence base. The review was limited by the lack of high quality, rigorously designed studies and the shortcomings of exposure and outcome measures used in the included studies. Disaster exposure was often measured ecologically or by proxy measures and few measured different individual levels of exposure or disaster affectedness. The measurement of VAWG was similarly problematic with few studies using a scale of violent acts experienced and even fewer using validated scales. Notably, no study used the WHO Violence Against Women measures that are validated and standardised measures in VAWG research. ${ }^{32}$ Some studies also measured VAWG several years after the exposure event which introduces recall bias, while variations in time scales between studies also limits comparison. The inclusion of English only articles and the overrepresentation of evidence from events in the USA (eg, Hurricane Katrina) and Haiti may have resulted in publication bias and limits the generalisability of the review.

Our findings have implications for future research. First, to address measurement issues, studies should carefully consider the IPV and other VAWG metrics to be included to ensure that they capture internationally validated measures that are sensitive to disaster effects. In addition, advancing the measurement of disaster exposure for related research merits further attention, such as the use of ecological approaches like spatial data on residency and disaster severity. Relatedly, as highlighted earlier, the complexities of reporting VAWG highlights the need for more robust longitudinal and/or comparative studies. Second, the scope can be expanded by including non-English studies and including additional 
search terms for VAWG, such as forced early marriage, trafficking and sexual exploitation that were found to be relevant in this context. Finally, apart from strengthening study designs to better estimate linkages between disasters and VAWG, we need studies that also start to unpack the association between climate-related change and environmental degradation and impacts on VAWG.

\section{CONCLUSION}

To our knowledge, this is the first systematic evidence on the effects of exposure to disasters from natural hazards on VAWG. We present quantitative and qualitative evidence on increased VAWG after disaster exposure and have developed a conceptual framework with three hypothesised pathways to explain this association. More high-quality research with greater geographical scope and use of standardised exposure and outcome measures is critical to generate further knowledge on the magnitude of the issue and mechanisms. As populations are increasingly affected by climate-related disasters and VAWG can have severe and lasting health impacts, existing knowledge must inform rapid action across policy and practice. At the policy level, greater awareness on disaster related VAWG, gender-sensitive DRR policies and inclusion of women in disaster management is critical. Social protection programmes that address the underlying drivers of VAWG, such as poverty and economic insecurity, could be designed to be gender-sensitive. Further, systems for rapid and effective coordination between disaster management, law enforcement and health authorities must be defined clearly to prevent VAWG and address its health consequences.

Contributors AMT and MR designed the study protocol and conducted the search, data extraction and analysis. All authors contributed to the synthesis of results and writing and editing drafts. AMT wrote the first draft and all authors reviewed and provided inputs for subsequent drafts. All authors prepared and approved the final article.

Funding The authors have not declared a specific grant for this research from any funding agency in the public, commercial or not-for-profit sectors.

Competing interests None declared.

\section{Patient consent for publication Not required.}

Ethics approval All data used in this review were already in the public domain and ethical approval was not required.

Provenance and peer review Not commissioned; externally peer reviewed.

Data availability statement Data are available in a public, open access repository. No additional data are available.

Supplemental material This content has been supplied by the author(s). It has not been vetted by BMJ Publishing Group Limited (BMJ) and may not have been peer-reviewed. Any opinions or recommendations discussed are solely those of the author(s) and are not endorsed by BMJ. BMJ disclaims all liability and responsibility arising from any reliance placed on the content. Where the content includes any translated material, BMJ does not warrant the accuracy and reliability of the translations (including but not limited to local regulations, clinical guidelines, terminology, drug names and drug dosages), and is not responsible for any error and/or omissions arising from translation and adaptation or otherwise.

Open access This is an open access article distributed in accordance with the Creative Commons Attribution Non Commercial (CC BY-NC 4.0) license, which permits others to distribute, remix, adapt, build upon this work non-commercially, and license their derivative works on different terms, provided the original work is properly cited, appropriate credit is given, any changes made indicated, and the use is non-commercial. See: http://creativecommons.org/licenses/by-nc/4.0/.

\section{ORCID iDs}

Alyssa Mari Thurston http://orcid.org/0000-0002-5860-1664

Heidi Stöckl http://orcid.org/0000-0002-0907-8483

Meghna Ranganathan http://orcid.org/0000-0001-5827-343X

\section{REFERENCES}

1 CRED. Un office for disaster risk reduction. human cost of disasters: an overview of the last 20 years 2000-2019, 2020: 28.

2 Watts N, Amann M, Arnell N, et al. The 2019 report of the Lancet countdown on health and climate change: ensuring that the health of a child born today is not defined by a changing climate. Lancet 2019;394:1836-78

3 Intergovernmental Panel on Climate Change (IPCC). Global warming of $1.5^{\circ} \mathrm{C}$ : an IPCC special report on the impacts of global warming of $1.5^{\circ} \mathrm{C}$ above pre-industrial levels and related global greenhouse gas emission pathways, in the context of strengthening the global response to the threat of climate change. Geneva: IPCC, 2018: 630. https://www.ipcc.ch/sr15/download/\#full

4 International Federation of Red Cross and Red Crescent Societies (IFRC). 2018 world disasters report: leaving no one behind. Geneva: IFRC, 2018: 145 p. https://media.ifrc.org/ifrc/wp-content/uploads/ sites/5/2018/10/B-WDR-2018-EN-LR.pdf

5 Bartlett S. Climate change and urban children: impacts and implications for adaptation in low and middle income countries. IIED human settlements discussion paper - climate change and cities 2. London: International Institute for Environment and Development, 2008.

6 Visser $\mathrm{H}$, Petersen AC, Ligtvoet W. On the relation between weatherrelated disaster impacts, vulnerability and climate change. Clim Change 2014;125:461-77.

7 Cardona OD, van Aalst MK, Birkmann J. Determinants of risk: exposure and vulnerability. In: Field CB, Barros V, Stocker TF, eds. Managing the Risks of Extreme Events and Disasters to Advance Climate Change Adaptation: A Special Report of Working Groups I and II of the Intergovernmental Panel on Climate Change (IPCC) [book on the Internet. Cambridge: Cambridge University Press, 2012: 65-108.

8 Howard P, Livermore MA. Sociopolitical feedbacks and climate change. Harvard Environmental Law Review 2019;43.

9 United Nations Development Programme. Gender and disaster risk reduction. New York: UNDP, 2013: 6 p.

10 Ikeda K. Gender differences in human loss and vulnerability in natural disasters: a case study from Bangladesh. Indian J Gend Stud 1995;2:171-93.

11 Oxfam International. The tsunami's impact on women [Internet. Oxfam Briefing Note, 2005: 14. https://oxfamilibrary.openrepository. com/bitstream/handle/10546/115038/bn-tsunami-impact-onwomen-250305-en.pdf?sequence=1\&isAllowed=y

12 Neumayer E, Plümper T. The gendered nature of natural disasters: the impact of catastrophic events on the gender gap in life expectancy, 1981-2002. Annals of the Association of American Geographers 2007;97:551-66.

13 Enarson E. Through women's eyes: a gendered research agenda for disaster social science. Disasters 1998;22:157-73.

14 United Nations Office for Disaster Risk Reduction (UNDRR). Progress review and the way forward: gender equality and social inclusion in implementing the Sendai framework for disaster risk reduction in Asia. Asia Partnership Stakeholder Group on Gender Issues, 2018: 48. https://asiapacific.unwomen.org/en/digital-library/ publications/2018/ 12/progress-review-and-the-way-forward

15 UNDRR. Sendai framework for disaster risk reduction 2015-2030. New York: UNISDR, 2015: 32. https://www.undrr.org/publication/ sendai-framework-disaster-risk-reduction-2015-2030

16 Plan International. In Double Jeopardy: Adolescent Girls and Disasters-Because I am a Girl: The State of the World's Girls 2013. Plan International, 2013: 220. https://plan-international.org/ publications/state-worlds-girls-2013-adolescent-girls-and-disasters

17 True J. Gendered violence in natural disasters: learning from new Orleans, Haiti and Christchurch. Aotearoa New Zealand Social Work 2013;25:78-89.

18 CARE International in Mozambique. Hope dries up? Women and Girls coping with Drought and Climate Change in Mozambique [Internet. CARE, 2016: 19. https://www.care-international.org/files/ files/El_Nino_Mozambique_Report_final.pdf 
19 International Federation of Red Cross and Red Crescent Societies (IFRC). Unseen, unheard: Gender-based violence in disasters [Internet. Geneva: IFRC, 2015: 52. https://www.ifrc.org/Global/ Documents/Secretariat/201511/1297700_GBV_in_Disasters_EN LR2.pdf

20 Masson L V, Lim S, Budimir M. Disasters and violence against women and girls: Can disasters shake social norms and power relations? [Internet]. Overseas Development Institute Working Paper. 22p, 2016. Available: https://www.refworld.org/pdfid/583c0c744.pdf [Accessed 8 Sep 2020].

21 World Health Organization (WHO). Global and regional estimates of violence against women: prevalence and health effects of intimate partner violence and nonpartner sexual violence. Geneva: WHO, 2013. https://apps.who.int/iris/bitstream/handle/10665/85239/ 9789241564625_eng.pdf?sequence $=1$

22 Cerna-Turoff I, Fischer H-T, Mayhew S, et al. Violence against children and natural disasters: a systematic review and metaanalysis of quantitative evidence. PLoS One 2019;14:e0217719.

23 WHO. Violence against women [Internet]. WHO, 2017. Available: https://www.who.int/news-room/fact-sheets/detail/violence-againstwomen [Accessed 02 Sep 2020].

24 Bacchus LJ, Ranganathan M, Watts C, et al. Recent intimate partner violence against women and health: a systematic review and metaanalysis of cohort studies. BMJ Open 2018;8:e19995.

25 Human Rights Watch. Nobody Remembers Us": Failure to Protect Women's and Girls' Right to Health and Security in Post-Earthquake Haiti. New York: HRW, 2011: 84. https://www.hrw.org/report/2011/ 08/19/nobody-remembers-us/failure-protect-womens-and-girlsright-health-and-security

26 Rezaeian M. The association between natural disasters and violence: a systematic review of the literature and a call for more epidemiological studies. J Res Med Sci 2013;18:1103-7.

27 Vu A, Adam A, Wirtz A, et al. The prevalence of sexual violence among female refugees in complex humanitarian emergencies: systematic review and meta-analysis. PLoS Curr 2014;6:ecurrents. dis.835f10778fd80ae031aac12d3b533ca7.

28 Stark L, Ager A. A systematic review of prevalence studies of gender-based violence in complex emergencies. Trauma Violence Abuse 2011;12:127-34.

29 Moher D, Liberati A, Tetzlaff J. Preferred reporting items for systematic reviews and meta-analyses: the PRISMA statement. The PRISMA group, 2009

30 United Nations Office for Disaster Risk Reduction. UNISDR Terminology on Disaster Risk Reduction [Internet], 2009. Available: https://www.undrr.org/terminology/disaster

31 Centre for Research on the Epidemiology of Disaster (CRED) Emergency events database (EM-DAT) general classifications, 2009. Available: https://www.emdat.be/classification

32 Garcia-Moreno C, Jansen H AFM, Ellsberg M. WHO Multi-country Study on Women's Health and Domestic Violence against Women. Geneva: WHO, 2005. https://www.who.int/reproductivehealth/ publications/violence/24159358X/en/

33 National Institutes of Health (NIH). Quality Assessment Tool for Observational Cohort and Cross-Sectional Studies [Internet]. NIH. Available: https://www.nhlbi.nih.gov/health-topics/study-qualityassessment-tools [Accessed cited 2020 Sep 9].

34 Critical Appraisal Skills Programme (CASP). Qualitative checklist [Internet]. CASP. Available: https://casp-uk.net/casp-toolschecklists/ [Accessed cited 2020 Sep 9].

35 Hong QN, Pluye P, Fabregues S. Mixed Methods Appraisal Tool (MMAT) Version 2018 User guide [Internet. Montreal: McGill University, 2018. http://mixedmethodsappraisaltoolpublic.pbworks. com/w/file/fetch/127916259/MMAT_2018_criteria-manual_2018-0801 ENG.pdf. (cited 2020 Sep 2).

36 Popay J, Roberts H, Sowden A. Guidance on the conduct of narrative synthesis in systematic reviews: a product from the ESRC methods programme, 2006.

37 Harville EW, Taylor CA, Tesfai H, et al. Experience of Hurricane Katrina and reported intimate partner violence. J Interpers Violence 2011;26:833-45.

38 Molyneaux R, Gibbs L, Bryant RA, et al. Interpersonal violence and mental health outcomes following disaster. BJPsych Open 2020;6:e1

39 Frasier PY, Belton L, Hooten E, et al. Disaster down East: using participatory action research to explore intimate partner violence in eastern North Carolina. Health Educ Behav 2004;31:69S-84.

40 Epstein A, Bendavid E, Nash D, et al. Drought and intimate partner violence towards women in 19 countries in sub-Saharan Africa during 2011-2018: A population-based study. PLoS Med 2020;17:e1003064.
41 Sanz-Barbero B, Linares C, Vives-Cases C, et al. Heat wave and the risk of intimate partner violence. Sci Total Environ 2018;644:413-9.

42 Rao S. A natural disaster and intimate partner violence: evidence over time. Soc Sci Med 2020;247:112804.

43 Weitzman A, Behrman J. Disaster, disruption to family life, and intimate partner violence: the case of the 2010 earthquake in Haiti. Sociol Sci 2016;3:167-89.

44 Straus M, Hamby S, Boney-McCoy S. The revised conflict tactics scales (CTS2): development and preliminary psychometric data. Journal of Family Issues;17:283-316.

45 Smith PH, Earp JL, DeVellis R. Measuring battering: Development of the Women's Experience with Battering (WEB) scale. Women's Health: Research on Gender, Behavior, and Policy 1995;1:273-88.

46 Temple JR, van den Berg P, Thomas JF, et al. Teen dating violence and substance use following a natural disaster: does evacuation status matter? Am J Disaster Med 2011;6:201-6.

47 Anastario M, Shehab N, Lawry L. Increased gender-based violence among women internally displaced in Mississippi 2 years postHurricane Katrina. Disaster Med Public Health Prep 2009;3:18-26.

48 Sakurai K, Nishigori H, Nishigori T, et al. Incidence of domestic violence against pregnant females after the great East Japan earthquake in Miyagi Prefecture: the Japan environment and children's study. Disaster Med Public Health Prep 2017;11:216-26.

49 Campbell DW, Campbell JC, Yarandi HN, et al. Violence and abuse of internally displaced women survivors of the 2010 Haiti earthquake. Int J Public Health 2016;61:981-92.

50 Cerna-Turoff I, Kane JC, Devries K, et al. Did internal displacement from the 2010 earthquake in Haiti lead to long-term violence against children? A matched pairs study design. Child Abuse Negl 2020;102:104393.

51 Madkour AS, Johnson CC, Clum GA, et al. Disaster and youth violence: the experience of school-attending youth in New Orleans. $J$ Adolesc Health 2011;49:213-5.

52 Fagen JL, Sorensen W, Anderson PB. Why not the University of new Orleans? social disorganization and sexual violence among internally displaced women of Hurricane Katrina. J Community Health 2011;36:721-7.

53 Kolbe AR, Hutson RA, Shannon $\mathrm{H}$, et al. Mortality, crime and access to basic needs before and after the Haiti earthquake: a random survey of Port-au-Prince households. Med Confl Surviv 2010:26:281-97.

54 Lai BS, Osborne MC, De Veauuse-Brown N, et al. Violence victimization and negative health correlates of youth in postearthquake Haiti: findings from the cross-sectional violence against children survey. J Affect Disord 2020;270:59-64.

55 Azad AK, Hossain KM, Nasreen M. Flood-induced vulnerabilities and problems encountered by women in northern Bangladesh. International Journal of Disaster Risk Science 2013;4:190-9.

56 Tanoue K, Nishigori H, Watanabe Z, et al. Interannual changes in the prevalence of intimate partner violence against pregnant women in Miyagi Prefecture after the great East Japan earthquake: the Japan environment and children's study. J Interpers Violence 2019:886260519881517.

57 Sahni V, Scott AN, Beliveau M, et al. Public health surveillance response following the southern Alberta floods, 2013. Can J Public Health 2016;107:e142-8.

58 Sloand $\mathrm{E}$, Killion $\mathrm{C}$, Yarandi $\mathrm{H}$, et al. Experiences of violence and abuse among internally displaced adolescent girls following a natural disaster. J Adv Nurs 2017;73:3200-8.

59 Chan KL, Zhang Y. Female victimization and intimate partner violence after the may 12,2008 , Sichuan earthquake. Violence Vict 2011;26:364-76.

60 Logie $\mathrm{CH}$, Daniel C, Ahmed U, et al. 'Life under the tent is not safe, especially for young women': understanding intersectional violence among internally displaced youth in Leogane, Haiti. Glob Health Action 2017;10:1270816.

61 Bermudez LG, Stark L, Bennouna C, et al. Converging drivers of interpersonal violence: findings from a qualitative study in posthurricane Haiti. Child Abuse Negl 2019;89:178-91.

62 Rezwana N, Pain R. Gender-Based violence before, during and after cyclones: slow violence and layered disasters. Disasters 2020. doi:10.1111/disa.12441. [Epub ahead of print: 14 May 2020].

63 Sohrabizadeh S. A qualitative study of violence against women after the recent disasters of Iran. Prehosp Disaster Med 2016;31:407-12

64 Fisher S, Women VA. Violence against women and natural disasters: findings from post-tsunami Sri Lanka. Violence Against Women 2010;16:902-18.

65 Parkinson D, Zara C. The hidden disaster: domestic violence in the aftermath of natural disaster. Australian Journal of Emergency Management 2013;28:28-35. 
66 Rahill GJ, Joshi M, Lescano C, et al. Symptoms of PTSD in a sample of female victims of sexual violence in post-earthquake Haiti. $J$ Affect Disord 2015;173:232-8.

67 Yoshihama M, Yunomae T, Tsuge A, et al. Violence against women and children following the 2011 great East Japan disaster: making the invisible visible through research. Violence Against Women 2019;25:862-81.

68 Nguyen HT. Gendered vulnerabilities in times of natural disasters: male-to-female violence in the Philippines in the aftermath of super Typhoon Haiyan. Violence Against Women 2018;25:421-40.

69 Standing K, Parker S, Bista S. Grassroots responses to violence against women and girls in post-earthquake Nepal: lessons from the field. Gender \& Development 2016;24:187-204.

70 Rees S, Pittaway E, Bartolomei L. Waves of violence - Women in post-tsunami Sri Lanka. Australasian Journal of Disaster and Trauma Studies 2005;2005:19-27.

71 Parkinson D. Investigating the increase in domestic violence post disaster: an Australian case study. J Interpers Violence 2019;34:2333-62.

72 Irshad H, Mumtaz Z, Levay A. Long-Term gendered consequences of permanent disabilities caused by the 2005 Pakistan earthquake. Disasters 2012;36:452-64.

73 Sohrabizadeh S, Jahangiri K, Jazani RK. Women's challenges and capabilities in disasters: A case report of the twin earthquakes of Eastern Azerbaijan, Iran. PLoS Currents 2017;8.

74 Nguyen HT, Rydstrom H. Climate disaster, gender, and violence: Men's infliction of harm upon women in the Philippines and Vietnam. Womens Stud Int Forum 2018;71:56-62.

75 Plan International. Weathering the storm: adolescent girls and climate change. Plan International, 2011: 44. http://www.ungei.org/ weatherTheStorm.pdf

76 Australian Red Cross. Responding to gender-based violence in emergencies. Carlton, VIC: Australian Red Cross, 2013: 7. https://reliefweb.int/sites/reliefweb.int/files/resources/gender\% 20violence.pdf
77 Cutter SL. The forgotten casualties redux: women, children, and disaster risk. Global Environmental Change 2017;42:117-21.

78 Weidmann NB, Zürcher C. How wartime violence affects social cohesion: the Spatial-Temporal gravity model. Civil Wars 2013;15:1-18.

79 Calo-Blanco A, Kovář́l J, Mengel F, et al. Natural disasters and indicators of social cohesion. PLoS One 2017;12:e0176885.

80 Kaniasty K, Norris FH. In search of altruistic community: patterns of social support mobilization following Hurricane Hugo. Am J Community Psychol 1995;23:447-77.

81 Siegel JM, Bourque LB, Shoaf KI. Victimization after a natural disaster: social disorganization or community cohesion? Int J Mass Emerg Disasters 1999;17:265-94.

82 Moreno J, Shaw D. Women's empowerment following disaster: a longitudinal study of social change. Nat Hazards 2018;92:205-24.

83 Gracia E. Unreported cases of domestic violence against women: towards an epidemiology of social silence, tolerance, and inhibition. J Epidemiol Community Health 2004;58:536-7.

84 UN Women. COVID-19 and ending violence against women and girls. UN Women, 2020: 10. https://www.unwomen.org/en/digitallibrary/publications/2020/04/issue-brief-covid-19-and-endingviolence-against-women-and-girls

85 Peterman A, Potts A, O'Donnell M. Pandemics and violence against women and girls. Washington, DC: Center for Global Development, 2020: 528.

86 Peterman A, O'Donnell M. COVID-19 and violence against women and children: a second research round up. center for global development: CGD note, 2020. Available: https://www.cgdev.org/ sites/default/files/covid-19-and-violence-against-women-andchildren-second-research-round.pdf

87 Onyango MA, Resnick K, Davis A. Gender-Based Violence Among Adolescent Girls and Young Women: A Neglected Consequence of the West African Ebola Outbreak. In: Schwartz D, Anoko J, Abramowitz S, eds. Pregnant in the time of Ebola. global maternal and child health. Springer, 2019 